\title{
Nutritional assessment of a population with a history of childhood craniopharyngioma seen at Hospital "Prof. Dr. Juan P. Garrahan"
}

\author{
Carolina Caminiti, M.D. ${ }^{a}$, Carola Saure, M.D. ${ }^{a}$, Ilanit Bomer, M.D. ${ }^{a}$, \\ Mercedes Brea, B.S. ${ }^{b}$ and Javier González Ramos, M.D. ${ }^{c}$
}

\begin{abstract}
Introduction. Craniopharyngiomas are histologically benign malformations located between the pituitary and hypothalamus that may affect key hormone secretion for endocrine regulation and satiety modulation. Although this is a relatively benign disease, the combination of severe hypothalamic obesity and associated comorbidities results in a reduced quality of life. Objective. To assess the nutritional status of patients after craniopharyngioma surgery.

Population and Methods. Patients younger than 21 years old at the time of the study who required craniopharyngioma surgery at Hospital de Pediatría Garrahan and who signed an informed consent. Anthropometric characteristics, body composition by impedance analysis, energy expenditure by indirect calorimetry and energy intake were assessed. Insulin resistance and dyslipemia were estimated.
\end{abstract}

Results. A total of 39 patients were included; $41 \%$ had a normal weight and $59 \%$ were obese. Overall, $68 \%$ of patients had a central fat distribution; $40 \%$ had insulin resistance; and $32 \%$, dyslipemia. No significant differences were observed in terms of insulin resistance, dyslipemia, energy expenditure at rest, or energy intake between normal weight and obese patients. Among obese patients, 77\% had a low energy expenditure, regardless of their percentage of lean body mass $(62 \pm 2.7 \%$ versus $61.2 \pm 1.8 \%$ of normal versus low energy expenditure at rest; $p=0.8$ ).

Conclusions. A total of $59 \%$ of the studied population was obese. No significant differences wereobservedinterms ofmetaboliccomplications between normal weight and obese patients. A lower energy expenditure was observed, regardless of the lean body mass percentage and a similar energy intake.

Key words: craniopharyngioma, obesity, energy expenditure, body composition, energy intake.

http:/ /dx.doi.org/10.5546/aap.2017.eng.43

E-mail address:

Carolina Caminiti, M.D.: carocaminiti@gmail.com

\section{Funding:}

None.

Conflict of interest:

None.

Received: 4-7-2016

Accepted: 8-29-2016 but may occur at any age.

These are histologically benign embryonic malformations derived from the ectoblastic remnants of the Rathke's pouch between the pituitary and hypothalamus, and may affect key hormone secretion for endocrine regulation and satiety modulation. ${ }^{2}$

Although this is a benign tumor and the survival rate of this disease is high, it is notably associated with morbidities, even if completely resected, ${ }^{3,4}$ especially severe obesity, which is generally refractory to treatment.

Childhood obesity, particularly with visceral fat distribution and regardless of its etiology, results in major complications, including insulin resistance, type 2 diabetes, hypertension, and cardiovascular disease, etc. ${ }^{5-8}$

A recent study ${ }^{9}$ found, during the longitudinal follow-up of patients after craniopharyngioma surgery, that obesity at the time of diagnosis was a predictor of obesity at 5 years after resection. This may support hypothalamic involvement as the main risk factor for obesity in these patients. ${ }^{10}$

In addition, insulin resistance measured using the homeostasis assessment model (HOMA) before the surgery correlates to post-operative weight gain. ${ }^{11,12}$

Although this is a relatively benign disease, the combination of severe hypothalamic obesity and associated comorbidities results in a reduced quality of life. ${ }^{13}$

Based on the preceding concepts, we proposed to study the presence of obesity and metabolic complications in a cohort of patients under follow- 
up at this hospital after the resection of childhood craniopharyngioma.

Objective: To assess the nutritional status of patients after craniopharyngioma surgery.

\section{POPULATION AND METHODS}

All patients seen at the Department of Neurosurgery of Hospital de Pediatría Garrahan in the 2000-2012 period who had been diagnosed with craniopharyngioma and agreed to participate in the study by signing an informed consent were recruited. Patients who were older than 21 years old at the time of the study were excluded.

Patients' weight was measured using a beam scale with a $100 \mathrm{~g}$ precision, and their height was measured using a wall altimeter graduated in $\mathrm{cm}$ and $\mathrm{mm}$. The weight/age and height/age percentiles were estimated using the World Health Organization's (WHO) standards for patients younger than 60 months old, and Argentine tables were used for older patients. ${ }^{14}$ The body mass index (BMI) was estimated using the kilograms per square meters formula. The BMI/age percentile was established using the WHO standards for 0-19-year-old individuals. A BMI $=$ P5 $<$ P85 (2 to $<1$ standard deviations [SD]) was classified as normal weight; a BMI $\geq$ P85 < P95 (1 to < 2 SD), as overweight; and a BMI $\geq$ P95 ( $\geq 2$ SD), as obese. Patients' waist circumference was measured using a non-extensible tape measure positioned at the midline between the last rib and the iliac crest. Centralized fat mass was defined as > P90 (Freedman's tables). Blood pressure (BP) was recorded using a cuff that covered two-thirds of the upper arm, with the patient in sitting position and after resting for 10 minutes; the $\mathrm{BP} /$ age percentile was estimated using the Task Force references. ${ }^{15}$ Hypertension (HTN) was assumed in the case of a systolic and/or diastolic BP $\geq$ P95. The presence of fatty liver was assessed using an abdominal ultrasound.

The following lab tests were done after 12 hours of fasting: blood glucose level by the glucose oxidase method (normal: up to $110 \mathrm{mg} / \mathrm{dL}$ ); insulin by radioimmunoassay (normal: up to $15 \mu \mathrm{U} / \mathrm{L}$ in children and up to $20 \mu \mathrm{U} / \mathrm{L}$ in adolescents); total cholesterol and triglycerides by the CHOD-PAP-enzymatic colorimetric method; high-density lipoprotein cholesterol (HDL) and low-density lipoprotein cholesterol (LDL) by the CHOD-PAP method with heparin precipitation. Low HDL was defined as $<40 \mathrm{mg} / \mathrm{dL}$, hypertriglyceridemia as
$>110 \mathrm{mg} / \mathrm{dL}$. The HOMA was estimated using the baseline insulin $(\mu \mathrm{U} / \mathrm{L}) \mathrm{x}$ baseline glucose (mmol/L)/22.5 formula. Insulin resistance was defined as a HOMA $\geq 2.5$ in prepubertal and pubertal children. ${ }^{16}$

Body composition was estimated by monofrequency bioelectrical impedance analysis. ${ }^{17}$

Baseline energy expenditure was recorded using an indirect calorimetry measuring $\mathrm{O}_{2}$ consumption and $\mathrm{CO}_{2}$ production (CCM Express, MEDGRAPHICS) for 20 minutes after 20 minutes at rest.

Energy intake and energy distribution of macronutrients were assessed prospectively using a 3-day diet registry specially designed for this study. The sample registry sheet is attached (see Annex).

Date and age at the time of the surgery, radiation requirement, hormone replacement, antiepileptic and psychiatric drug use after the surgery were recorded.

\section{Statistical analysis}

The statistical software package used was STATA/SE11. Each outcome measure behavior was analyzed and reported as mean/SD for normal outcome measures or as median/range for those with a biased distribution. Student's $t$ test and the Wilcoxon rank-sum test were used for normal and biased distribution outcome measures, respectively. Categorical outcome measures were analyzed using the $\chi^{2} /$ Fisher test. A two-tailed test and a statistical significance of $p<0.05$ were assumed.

\section{RESULTS}

The accessible population was made up of 70 patients. Fifty-seven families were contacted on the telephone or by mail. Of these, 11 patients had died in the long-term post-operative period and 7 did not attend the scheduled visit. In the end, the percentage of the accessible population included in the research (sample) was 55\% (39 patients). Of them, $54 \%$ were girls. Patients' median age was 12.2 years old (2.5-19.1 years old), and the median time elapsed between the surgery and the assessment was 4.6 years (0.19-11.8 years).

Summary and dispersion statistics of demographic and clinical outcome measures corresponding to the studied population are described in Table 1.

As per the anthropometric nutritional assessment, $41 \%(16 / 39)$ of patients had a 
normal weight and 59\% (23/39) were obese. No patient was categorized as overweight, so the analysis was done considering normal weight and obese subjects. As per waist circumference, $68 \%$ of patients had a central fat distribution. Ten patients $(25 \%)$ had a low height/age.

Only one patient had HTN on the day of the assessment and was referred for follow-up. An abdominal ultrasound was scheduled for $12 / 39$ patients; $50 \%$ had hepatic steatosis.

Biochemical outcome measures are shown in Table 2. All patients had a normal blood glucose level. Forty percent of patients had insulin resistance as per the HOMA. In addition, 12 patients $(32 \%)$ had dyslipemia (hypo-HDL and/or hypertriglyceridemia).

Table 3 describes body composition and energy expenditure outcome measured in the studied population.

The mean energy intake was $1993 \pm 658$ daily calories (1708-2277 calories/day). The distribution of the percentage of energy from macronutrients was $40.4 \%(9.8-60 \%)$ from carbohydrates, $16.1 \%$ (10.6-38.2\%) from proteins, and 43\% (19-57\%) from fat.

TABLE 1: Demographic and anthropometric outcome measures of the 39 patients

\begin{tabular}{lcc}
\hline Outcome measures & Median & Range \\
\hline Age (years old) & 12.2 & 2.5 a 19.1 \\
Weight $(\mathrm{kg})$ & 50.6 & 17.3 a 170.2 \\
Weight Z-score & 1.1 & -2.6 a 10.3 \\
Height $(\mathrm{cm})$ & 140.3 & 82 a 178 \\
Height Z-score & -0.9 & -3.7 a 1.9 \\
BMI & 25.6 & 17 a 61.4 \\
BMI Z-score & 2 & -1.6 a 7.7 \\
Mean waist circumference $(\mathrm{cm})$ & 89.7 & 58.5 a 149 \\
\hline
\end{tabular}

BMI: body mass index.

TABLE 2: Biochemical outcome measures of the 39 patients

\begin{tabular}{lcc}
\hline Outcome measures & Median & Range \\
\hline Blood glucose level $(\mathrm{mg} / \mathrm{dL})$ & 82 & $53-99$ \\
Insulin $(\mu \mathrm{U} / \mathrm{L})$ & 7.8 & 1.9 to 63.6 \\
HOMA & 1.53 & 0.24 to 13.9 \\
Total C (mg/dL) & 167 & 123 to 250 \\
HDL C (mg/dL) & 50.3 & 25 to 93 \\
LDL C (mg/dL) & 100 & 64 to 158 \\
Triglycerides (mg/dL) & 90 & 35 to 575 \\
GOT (IU/L) & 22 & 9 to 49 \\
GPT (IU/L) & 19 & 9 to 104 \\
\hline
\end{tabular}

HOMA: homeostasis model assessment; Total C: total cholesterol; HDL C: HDL cholesterol; LDL C: LDL cholesterol; GOT: glutamic oxaloacetic transaminase; GPT: glutamic pyruvic transaminase.
Radiotherapy had been used as adjuvant treatment in 23\% (9/39) of patients. Endocrine disorders were observed in the form of panhypopituitarism in $95 \%$ of patients, for which replacement therapy with levothyroxine, desmopressin, and hydrocortisone was used. Growth hormone had been administered to $41 \%$ of patients. Among boys, 38\% received testosterone. Anticonvulsant agents were required by $25 \%$, and two patients were on risperidone due to behavior disorders. Among all assessed patients, only one reported he was not properly taking his medication so he was referred for multidisciplinary follow-up.

Afterward, the patient population was analyzed for the presence or absence of obesity: BMI Z-score of 3.7 (2 to 7.7) versus 1.23 (-1.69 to 1.92$), p<0.01$, respectively. No significant differences were observed in the age of patients with a normal BMI versus obese patients $(13.5 \pm 4.4$ years old versus $10 \pm 4.9$ years old; $p=0.08)$.

Fifteen patients (38\%) were younger than 6 years old at the time of the surgery. BMI Z-score among patients younger than 6 years old was higher than among older patients; however, no statistical significance was achieved (BMI Z-score of $3.1 \pm 1.99$ versus $2.2 \pm 2, p=0.17$ ).

In relation to the scale of obesity as per the presence or absence of diabetes insipidus, in our population it was observed that patients with this morbidity $(35 / 39)$ after the surgery had a BMI Z-score of $2.7 \pm 0.33$ versus $0.4 \pm 0.04$ in those who did not require treatment with desmopressin (3/39); the difference was not statistically significant $(p=0.06)$. The waist circumference was significantly smaller in the subgroup with a normal BMI $(76.6 \pm 13.1$ versus $96.8 \pm 23, p<0.01)$.

TABLE 3: Body composition and energy expenditure at rest in the 39 patients

\begin{tabular}{lcc}
\hline Outcome measures & Median & Range \\
\hline Lean body mass $(\mathrm{kg})$ & 31.5 & 16.1 to 96 \\
Lean body mass $(\%)$ & 67.9 & 53.4 to 95 \\
Fat body mass $(\mathrm{kg})$ & 14.3 & 1.2 to 74.5 \\
Fat body mass $(\%)$ & 32 & 4.9 to 46.9 \\
EER & $1257 \pm 486$ & 1087 to 1426 \\
$\%$ of predicted EER & $87 \pm 27.9$ & 90 to 103 \\
\hline
\end{tabular}

EER: energy expenditure at rest measured using an indirect calorimetry.

$\%$ of predicted EER results from the comparison between the patient's EER and that estimated with the formula. 
When the outcome measure waist circumference was categorized as per the cutoff point, 31\% (5/16) and 82\% (19/23) of patients with a history of craniopharyngioma and with a normal BMI or obesity, respectively, had centralized fat mass (Fisher $<0.01$ ). No significant differences were observed in the presence of insulin resistance (Fisher $=0.08)$, dyslipemia (Fisher $=0.46)$, or steatosis (Fisher $=0.54$ ) between both groups.

No significant differences were observed in any of the studied biochemical outcome measures in both patient subgroups.

Table 4 describes the body composition and energy expenditure outcome measures. No significant differences were observed in terms of energy expenditure at rest (EER) between patients with a normal BMI and obesity whereas, by definition, obese patients had a higher fat mass.

Then, tertiles were established by percentage of EER in the population of obese patients and the first tertile ( $82 \%$ of the predicted EER) was assumed as the cut-off point to categorize a normal versus a low EER. Among obese patients, $77 \%$ had a low energy expenditure.

A bivariate analysis was done of the percentage of lean body mass in the obese population based on a normal versus low EER and no significant differences were observed in the percentage of lean body mass between both groups (percentage of lean body mass: $62 \pm 2.7$ with a normal EER versus $61.2 \pm 1.8$ with a low EER; $p=0.8$ ).

In relation to energy intake, no statistically significant difference was observed between patients with a normal BMI versus those with obesity (2225 versus 1814 calories, $p=0.15$ ). An increased energy consumption from fat was detected in patients with a history of craniopharyngioma and a normal BMI compared to obese ones $(46.5 \%$ versus $37.8 \%, p=0.04)$.

\section{DISCUSSION}

Fifty-nine percent of patients (23/39) were obese. In relation to metabolic complications, $40 \%$ of patients had insulin resistance as measured by HOMA; $32 \%$ had dyslipemia (hypo-HDL and/or hypertriglyceridemia); and 50\% of patients with an abdominal ultrasound had fatty liver.

When the population of patients was analyzed in terms of presence or absence of obesity, no significant differences were observed in relation to age. Obese patients had a higher level of central fat mass distribution than normal-weight ones, and no differences were observed in relation to metabolic complications in both groups.

Also, no significant differences were observed in terms of EER between normal BMI and obese patients. Among obese patients, $77 \%$ had a low energy expenditure. No significant differences were found in the percentage of lean body mass in the obese population in terms of normal versus low EER. Energy intake was similar between normal weight and obese patients.

A recent study confirms that mortality among patients with a history of craniopharyngioma, especially during childhood and accompanied by hypopituitarism, is greater than in the general population. ${ }^{18}$ According to different studies, mortality caused by cardiovascular disease is 3 to 19 times higher compared to the general population. ${ }^{19}$

The scale of obesity and the proportion observed in our study is consistent with that described by several authors: between $22 \%$ and $75 \% .{ }^{20-23}$

A recent study (in press) found that the population with a history of childhood craniopharyngioma before 6 years old gained weight faster and had a greater scale of obesity compared to patients older than 6 years old (BMI Z-score: $3.8 \pm 1.3$ versus $2.7 \pm 0.6$, respectively). ${ }^{24}$ In our study, no statistically significant differences

TABLE 4: Body composition and energy expenditure of patients with a normal body mass index versus obese patients

\begin{tabular}{lcccc}
\hline Outcome measures & \multicolumn{2}{c}{ Normal BMI (n= 16) } & \multicolumn{2}{c}{ Obese (n= 23) } \\
& Median & Range & Median & Range \\
\hline Lean body mass (kg) & 29.8 & 16.1 to 56.7 & 32.6 & 17.5 to 96 \\
Lean body mass (\%) & 73.5 & 56.9 to 95 & 62.4 & 53.4 to 75.1 \\
Fat body mass (kg) & 13.2 & 1.2 to 22.8 & 20.1 & 7.5 to 74.5 \\
Fat body mass (\%) & 26.4 & 4.9 to 43 & 37.5 & 24.8 to 46.5 \\
EER & $1212 \pm 355$ & 618 to 2031 & $1297 \pm 586$ & 548 to 2603 \\
\% of predicted EER & $94 \pm 27$ & 38 to 134 & $81 \pm 27$ & 48 to 137 \\
\hline
\end{tabular}

BMI: body mass index; NS: not significant; EER: energy expenditure at rest measured by indirect calorimetry.

$\%$ of predicted EER results from the comparison between the patient's EER and that estimated with the formula. 
were observed in the scale of obesity between patients who were diagnosed and had the surgery before and after turning 6 years old.

Hypothalamic involvement before the surgery is associated with developing obesity after the surgery, ${ }^{25}$ as adjusted by sex, age, and BMI at the time of the surgery, presence of hydrocephalus and residual tumor. Thus, it was also observed that diabetes insipidus acted as an endocrine marker of risk for hypothalamic obesity. ${ }^{12}$ On the contrary, in our study, no statistically significant differences were observed in the scale of obesity between patients with and without diabetes insipidus. However, the difference in the BMI Z-score was overwhelming: $64 \%$ of patients with diabetes insipidus were obese whereas all those without this condition had a normal weight. Probably, the small size of the sample of patients without hypopituitarism hindered the possibility of finding differences between both populations.

In terms of low height frequency, a recently published study by Kalina et al. ${ }^{26}$ conducted in 22 patients with a history of craniopharyngioma with follow-up for 5 years observed that $40 \%$ had a low height; in our study, however, the rate of low height was $25 \%$. Such difference, in spite of the similar mean follow-up period, may be explained by the fact that our patients were assessed in a range of 0.19 to 11.8 years after the surgery, which may have underestimated the presence of low height that could be observed over a longer follow-up period.

Also, $40 \%$ of studied patients had insulin resistance, and $32 \%$ had dyslipemia, which is consistent with other authors who observed a frequency of $30 \%$ and $39 \%$, respectively. ${ }^{27}$

However, in the above-mentioned study by Kalina et al., the prevalence of metabolic disorders was higher: $68.2 \%$ of patients had insulin resistance and $86 \%$, dyslipemia. Such difference may be explained by the fact that their population had a higher obesity prevalence than ours ( $81.8 \%$ versus $59 \%$ ) and, therefore, a higher risk for metabolic complications.

No significant differences were observed in the presence of insulin resistance once patients were categorized by BMI, although obese patients had a higher level of central fat mass distribution. There is no consensus in relation to such metabolic complication in the literature. In another study conducted by our team ${ }^{28}$ that compared obese patients with a history of craniopharyngioma to a group of 43 patients with obesity of multifactorial etiology paired by sex and age found no significant differences in the scale of obesity, centralized fat mass by waist circumference, insulin resistance ( $52 \%$ versus $68 \%, p=0.2)$, dyslipemia $(p=0.68)$, or hepatic steatosis $(p=0.34)$ between both groups.

Similarly to what was described in the study by Sahakitrungruang et al. ${ }^{29}$ our study found that $50 \%$ of patients had fatty liver as observed in the abdominal ultrasound.

A recent study confirms that mortality among patients with a history of craniopharyngioma, especially during childhood and accompanied by hypopituitarism, is greater than in the general population. ${ }^{18}$ According to different studies, mortality caused by cardiovascular disease in these patients is 3 to 19 times higher compared to the general population. ${ }^{30}$

Body composition was similar in terms of percentage; however, once BMI was categorized, patients with a normal BMI had a higher percentage of lean body mass and a lower percentage of fat body mass than their obese peers. In the above-mentioned study, ${ }^{30}$ obese patients with a history of craniopharyngioma had a lower percentage of lean body mass and a higher percentage of fat body mass compared to those with obesity of multifactorial etiology, and a lower and statistically significant EER $(1297 \pm 586$ versus $1721 \pm 469, p<0.01$ ), regardless of their lean body mass.

No statistically significant differences were found in this study in relation to EER between normal weight and obese patients. In addition, $77 \%$ of obese patients had a low EER, which is consistent with previous publications. ${ }^{31}$

Besides, a low EER persisted regardless of the lean body mass percentage, which supports the fact that there may be other factors that reduce energy expenditure in this group of patients.

Lastly, in relation to energy intake, no significant differences were found in patients with craniopharyngioma as per BMI, similar to what was reported in previous publications, ${ }^{32}$ which concluded that, once hypothalamic obesity occurs, it remains over time regardless of hyperphagia, probably due to the reduced energy expenditure. Hoffmann et al. compared eating behavior among patients with a history of craniopharyngioma and patients with obesity of multifactorial etiology, and no significant differences were observed between both groups. ${ }^{20}$

This study poses the following limitations: 1) the impossibility of contacting all patients who met the inclusion criteria due to missing personal data, especially those who had had the surgery 
a long time before; 2) the lack of a Tanner stage assessment; 3 ) the scarce number of patients categorized into the subgroups. Also, this study poses the following strengths: 1 ) the successful analysis of the entire accessible population of patients who had a craniopharyngioma surgery and were younger than 21 years old seen at the most relevant hospital for this disease at a national level; and 2) the prospective nature of the anthropometric and biochemical control, body composition, and EER of all studied patients.

\section{CONCLUSIONS}

In total, $59 \%$ of the population of patients with a history of craniopharyngioma were obese. Although obese patients were more likely to have a central fat mass distribution, no significant differences were observed between both groups in terms of metabolic complications.

A lower energy expenditure not related to lean body mass and a similar energy intake were observed among patients with a history of craniopharyngioma regardless of their BMI.

Based on the predictable course of patients with craniopharyngioma, emphasis should be made on the need for an early intervention in order to prevent an increased weight gain.

\section{REFERENCES}

1. Bunin GR, Surawicz TS, Witman PA, Preston-Martin S, et al. The descriptive epidemiology of craniopharyngioma. J Neurosurg 1998;89(4):547-51.

2. Sanford RA. Craniopharyngioma: results of survey of the American Society of Pediatric Neurosurgery. Pediatr Neurosurg 1994;21(Suppl 1):39-43.

3. Muller HL, Bueb K, Bartels U, Roth C, et al. Obesity after childhood craniopharyngioma: German multicenter study on pre-operative risk factors and quality of life. Klin Padiatr 2001;213(4):244-9.

4. Steinbok P. Craniopharyngioma in children: long-term outcomes. Nerol Med Chir (Tokyo) 2015,55(9):722-6.

5. Khan BB, Flier JS. Obesity and insulin resistance. J Clin Invest 2000;106(4):473-81.

6. Klein S, Burke LE, Bray GA, Blair S, et al. Clinical implications of obesity with specific focus on cardiovascular disease: a statement for professionals from the American Heart Association Council of Nutrition, Physical Activity, and Metabolism endorsed by the American College of Cardiology Foundation. Circulation 2004;11(18):2952-67.

7. Comité Nacional de Nutrición. Guías de práctica clínica para la prevención, el diagnóstico y el tratamiento de la obesidad. Arch Argent Pediatr 2011;109(3):256-66.

8. Comité Nacional de Nutrición. Obesidad: Guías para su abordaje clínico 2015. [Accessed on: September $1^{\text {st }}, 2016$ ]. Availableat:http://www.sap.org.ar/docs/profesionales / consensos/consenso_obesidad_guias_completo_para_ web.pdf.

9. Khan MS, Humayun KN, Donaldson M, Ahmed SF, et al. Longitudinal changes in body mass index in children with craniopharyngioma. Horm Res Paediatr 2014,82(6):372-9.

10. Muller HL, Emser A, Faldum A, Bruhnken G, et al.
LongitudinalStudy on Growth and Body Mass Index before and after Diagnosis of Childhood Craniopharyngioma. J Clin Endocrinol Metab 2004;89(7):3298-305.

11. Trivin C, Busiah K, Mahlarui N, Recansens C, et al. Childhood craniopharyngioma: greater hypothalamic involvement before surgery is associated with higher homeostasis model insulin resistance index. BMC Pediatr 2009;9:24.

12. Roth C, Eslamy $H$, Werny $D$, Elfers $C$, et al. Semiquantitative analysis of hypothalamic damage on MRI predicts risk for hypothalamic obesity. Obesity (Silver Spring) 2015;23(6):1226-33.

13. Yano S, Kudo M, Hide T, Shinojima N, et al. Quality of life and clinical features of long-term survivors surgically treated for pediatric craniopharyngioma. World Neurosurg 2016;85:153-62.

14. Comité Nacional de Crecimiento y Desarrollo. Guías para la evaluación del crecimiento. 2.da ed. Buenos Aires: SAP, 2001. [Accessed on: September 2016]. Available at: http://www.sap.org.ar/docs/profesionales/percentilos/ completo.pdf.

15. National High Blood Pressure Education Program Working Group on High Blood Pressure in Children and Adolescents. The Fourth Report on the Diagnosis, Evaluation and Treatment of High Blood Pressure in Children and Adolescents. Pediatrics 2004;114(2Suppl4th Report):555-76.

16. Singh Y, Garg MK,Tandon N, Marwaha RK. A study of insulin resistance by HOMA-IR and its cut-off value to identify metabolic syndrome in urban Indian adolescents. J Clin Res Pediatr Endocrinol 2013;5(4):245-51.

17. Houtkooper LB, Going SB, Lobman TG, Roche AF, et al. Bioelectrical impedance estimation of fat-free body mass in children and youth: a cross validation study. J Appl Physiol (1985) 1992;72(1):366-73.

18. Olsson D, Andersson E, Bryngelsson I, Nilsson A, et al. Excess mortality and morbidity in pactients with craniopharyngioma, especially in patients with childhood onset: a population-based study inSweden. JClin Endocrinol Metab 2015;100(2):467-74.

19. Erfurth EM. Endocrine aspects and sequel in patients with craniopharyngioma. J Pediatr Endocrinol Met 2015;28(1-2): 19-26.

20. Roth C. Hypothalamic obesity in patients with craniopharyngioma: profound changes of several weight regulatory circuits. Front Endocrinol (Lausanne) 2011;2:49.

21. Hoffmann A, Postma FP, Sterkenburg AS, Gebhardt $\mathrm{U}$, et al. Eating Behavior, weight problems and eating disorders in 101 long-term survivors of childhood onset craniopharyngioma. J Pediatr Endocrinol Metab 2015;28(12):35-43.

22. Rosenfeld A, Arrington D, Miller J, Olson M, et al. A review of childhood and adolescent craniopharyngiomas with particular attention of hypothalamic obesity. Pediatr Neurol 2014;50(1):4-10.

23. Rath SR, Lee S, Kotecha RS, Taylor M, et al. Childhood craniopharyngioma: 20-year institutional experience in Western Australia. J Paediatr Child Health 2013;49(5):403-8.

24. Haliloglu B, Atay Z, Güran T, Abali S, et al. Risk factors for mortality caused by hypothalamic obesity in children with hypothalamic tumors. Pediatr Obes 2015 (Epub ahead of print).

25. Muller H, Gebhardt U, Faldum A, Warmuth-Metz M, et al. Xanthogranuloma, Rathke's Cyst, and Childhood Craneopharyngioma: Results of Prospective Multinational Studies of Children and Adolescents with Rare Sellar Malformations. JClin Endocrinol Metab 2012;97(11):3935-43.

26. Kalina MA,WilczekM,Kalina-Faska B,Skala-Zamorowska $\mathrm{E}$, et al. Carbohydrate lipid profile and use of metformin 
with micronized fenofibrate in reducing metabolic consequences of craniopharyngioma treatment in children: single institution experience. J Pediatr Endocrinol Metabol 2015;28(1-2):45-51.

27. Adachi M, Tsuchiga T, Muroya K, Asakura Y, et al. Prevalence of obesity, hyperlipemia and insulin resistance in children with suprasellar brain tumors. Clin Pediatr Endocrinol 2007;16(1):1-9.

28. Bomer I, Saure C, Caminiti C, Gonzalez Ramos J, et al. Comparison of energy expenditure, body composition, metabolic disorders, and energy intake between obese children with a history of craniopharyngioma and children with multifactorial obesity. J Pediatr Endocrinol Metab 2015;28(11-12):1305-12.

29. Sahakitrungruang T, Klomchan T, Supoonseilchai V, WachavasndhuS. Obesity, metabolic syndrome and insulin dynamics in children after craniopharyngioma surgery. Eur J Pediatr 2011;170(6):763-9.

30. Erfurth EM. Endocrine aspects and sequel in patients with craniopharyngioma. J Pediatr Endocrinol Met 2015;28(1-2): 19-26.

31. Holmer H, Pozarek G, Wirfalt E, Popovic V, et al. Reduced Energy Expenditure and Impaired FeedingRelated Signals But Not High Energy Intake Reinforces Hypothalamic Obesity in Adults with Childhood Onset Craniopharyngioma. J Clin Endocrinol Metab 2010;95(12):5395-402.

32. Harz KJ, Müller H, Waldeck E, Pudel V, et al. Obesity in Patients with Craniopharyngioma: Assessment of Food Intake and Movement Counts Indicating Physical Activity. J Clin Endocrinol Metab 2003;88(11):5227-31. 


\section{ANNEX}

Diet registry sheet

\begin{tabular}{|c|c|c|c|c|c|c|c|c|c|c|c|}
\hline Day & Time & Meal & Quantity & Day & Time & Meal & Quantity & Day & Time & Meal & Quantity \\
\hline & & & & & & & & & & & \\
\hline & & & & & & & & & & & \\
\hline & & & & & & & & & & & \\
\hline & & & & & & & & & & & \\
\hline & & & & & & & & & & & \\
\hline & & & & & & & & & & & \\
\hline & & & & & & & & & & & \\
\hline & & & & & & & & & & & \\
\hline & & & & & & & & & & & \\
\hline & & & & & & & & & & & \\
\hline & & & & & & & & & & & \\
\hline & & & & & & & & & & & \\
\hline & & & & & & & & & & & \\
\hline
\end{tabular}

